\title{
Catalytic Fast Co-Pyrolysis of Sewage Sludge-Sawdust Using Mixed Metal Oxides Modified with ZSM-5 Catalysts on Dual-Catalysts for Product Upgrading
}

\author{
Nurul Afiqah Haji Morni ${ }^{1 *}$, Yeung Chun $\mathrm{Mo}^{2}$, Hong Tian ${ }^{3}$, Yang Yang ${ }^{4 *}$, \\ Neeranuch Phusunti ${ }^{5}$, Muhammad Saifullah Abu Bakar ${ }^{1}$, Abul Kalam Azad ${ }^{1}$ \\ ${ }^{1}$ Faculty of Integrated Technologies, University Brunei Darussalam, Jalan Tungku Link, Gadong, BE \\ 1410, Brunei Darussalam \\ ${ }^{2}$ Hong Kong Polytechnic University, Hung Hom, Kowloon, Hong Kong \\ ${ }^{3}$ School of Energy \& Power Engineering, Changsha University of Science \& Technology, Changsha \\ 410114, China \\ ${ }^{4}$ Bioenergy Research Group, European Bioenergy Research Institute (EBRI), Aston University, \\ Birmingham B4 7ET, UK \\ ${ }^{5}$ Department of Chemistry, Faculty of Science, Prince of Songkla University, Hat Yai, Songkhla, 90112, \\ Thailand \\ *afiqah.91n@gmail.com (Nurul Afiqah Haji Morni) \\ *y.yang6@aston.ac.uk; +44 (0) 1212043433 (Y. Yang)
}

\begin{abstract}
Catalytic fast co-pyrolysis of sewage sludge and sawdust was performed using Py/GC-MS for pyrolytic product upgrades. Metal oxides $\left(\mathrm{NiO}\right.$ and $\left.\mathrm{MoO}_{3}\right)$ and ZSM-5 catalysts had been introduced into single catalytic pyrolysis. The combination of $\mathrm{NiO}+\mathrm{MoO}_{3}$ in mixed metal oxides (MMOs) was modified with ZSM-5 under a dual-catalyst with different catalytic layouts. In the pyrolysis process, the metal oxides specifically promoted the formation of phenols, ketones, and furans. ZSM-5 was proven to be more effective in producing aromatic hydrocarbons and phenols and in reducing the oxygenated compounds. The combination of MMOs with ZSM-5 effectively improved product distribution by increasing the production of aromatics and phenols. MMOs promoted the aromatics selectivity of undesirable PAHs (70.5 \%), however, the addition of ZSM5 to MMOs appeared to reduce and inhibit the formation of PAHs by $0.85 \%$. The highest yield of aromatics was obtained by the layout of the ZSM-5/MMO dual catalysts layout which was 21.6 $\%$. Dual catalysts of MMOs and ZSM-5 in separated layout created promising effects in further
\end{abstract}


increasing the production of aromatic hydrocarbons and phenols compared to the mixture of MMOs modified ZSM-5.

Keywords: Catalytic fast co-pyrolysis; Py/GC-MS; ZSM-5; MMOs; Dual-catalysts; Aromatics

\author{
Abbreviations \\ CFP: Catalytic fast pyrolysis \\ Co-CFP: Catalytic fast co-pyrolysis \\ GC/MS: Gas chromatography/mass spectrometry \\ MMOs: Mixed metal oxides \\ $\mathrm{MoO}_{3}$ : Molybdenum trioxide \\ NCC Nitrogen-containing compounds \\ NiO: Nickel oxide
}

PAHs: Polycyclic aromatic hydrocarbons

Py/GC-MS: Pyrolyser/Gas Chromatography-Mass Spectrometry

SD: Sawdust

SS: Sewage sludge

ZSM-5: Zeolite

\title{
1. Introduction
}

Climate change has been the greatest challenge of the modern world faced by human beings because it is now at a critical moment. Increased wildfires, flooding, droughts, and decreasing water supplies are all attributed to climate change. Since the beginning of an industrial revolution, the intensive consumption of fossil fuels by oil-producing countries, carbon dioxide emissions are mainly the product from the burning of fossil fuels, resulting in a massive increase of greenhouse gases in the atmosphere, leading to global warming [1,2]. Renewables, including solar, wind, hydro, biofuels, and others, are at the centre of transition to a less carbon-intensive and more sustainable energy system. Biofuels, are by far the largest source of energy production and clean transport fuels, which have a potentially important role in reducing emissions compared to the use of oil products. It has numerous benefits for ensuring energy security to lowering emissions upon 
building cleaner and more secure energy systems. The support for conventional and novel biofuels should be introduced and practiced strongly in oil-importing countries around the world. The use of waste and residue feedstocks as biofuels feedstock can also provide deeper emission reductions of around 80-90 \% compared with fossil fuels for transport. The choice of feedstock and source of process energy used significantly affects the overall emissions reduction potential of biofuels. There is growing interest in the use of alternative feedstocks that can avoid the potential sustainability concerns associated with some conventional biofuels.

Pyrolysis is among the conversion routes that are used for converting solid waste and residue biomass feedstocks into liquid biofuels. It is a thermochemical conversion technology that the process occurs in the absence of oxygen to convert biomass into bio-char, bio-oil, and pyrolysis gas at elevated temperatures $[3,4]$. Bio-oil is a viscous free-flowing dark brown or black organic liquid obtained from pyrolysis containing a complex mixture of different compounds such as acids, aldehydes, ketones, furans, pyrans, sugars, benzenes, catechols, phenols, guaiacols, and syringols [5,6]. Despite the contained of oxygenated components in the bio-oil, this resulted in low high heating value, instability, corrosiveness and it is incompatible with petroleum fuel to be used directly as transportation fuel [7]. Therefore, to refine bio-oil, catalytic fast pyrolysis (CFP) is the most promising approach for upgrading the quality of bio-oil in terms of reducing the oxygenated components to meet the required specifications recommendation for petroleum fuel.

Recently, the catalytic fast co-pyrolysis (co-CFP) has gained more attention on the fundamental functions of catalyst in pyrolysis on reducing the activation energy, enhance selectivity, and decreasing the pyrolysis temperature in terms of reducing the equipment, energy costs, and increase the biomass conversion process [8,9]. With the presence of a catalyst, it provides the interaction of volatiles at the catalytic sites during pyrolysis and this interaction allows to improve the quality and quantity of bio-oil specifically in the aromatics yield and selectivity of the bio-oil product distribution, as a result, it modifies the distribution of the products [10]. The operating conditions, choices of feedstock, and catalyst play a significant role to maximise the quality of biooil which seems to be similar to refined petroleum fuel [11]. Various catalysts types including zeolites, metal oxides, transition metals, and bio-char based catalysts, have been applied in the CFP process to examine the composition and stability of bio-oil yields and properties. 
Zeolites are considered to be the most suitable catalysts for the production of aromatics via CFP technology [12]. The application of zeolite catalysts in CFP of biomass especially ZSM-5 has been extensively studied recently [13-16]. Zeolite catalytic cracking is found to be capable of deoxygenating the bio-oil components and enhance its fuel properties such as the production of aromatics hydrocarbon. Due to the acidic properties and shape selectivity that are effective to convert undesirable oxygenated compounds in bio-oil into aromatics, such as benzene, toluene, and xylene (BTX) [17-19]. This could upgrade the bio-oil into high-value chemicals as important in raw materials for the chemical industry. Pyrolysis oils have also been successfully tested and used in diesel engines as a substitute for diesel or heavy fuel [20,21]. Therefore, this would increase the demand in the fuel industry as well as an alternative in replacing the diesel from crude oil.

Another type of catalyst to be considered as a suitable choice is metal oxides due to their remarkable catalytic effects and wide availability. Oxygenated groups could be removed to produce $\mathrm{CO}_{2}, \mathrm{CO}$, and $\mathrm{H}_{2} \mathrm{O}$ thus making the pyrolysis bio-oil more stable [22]. This is due to these compounds are reactive. For instance, ketones, aldehydes, and organic acids react to form ethers, acetals, and hemiacetals. However, many studies had studied the effectiveness of different catalysts or processes on the bio-oil quality, whereas, it should also be pointed out on the bio-oil yield in determining the potential of a specific catalyst and process [23,24]. It should be noticed that the increase of bio-oil quality through deoxygenation is usually gained at the cost of great carbon loss, leading to a large drop in bio-oil yield and limiting the development of CFP technology [25].

Novel CFP technology such as the dual-catalyst catalytic method is a new development in solving said issue and could increase the yield of high-quality bio-oil [26,27]. Dual catalysts on CFP have been commonly studied via analytical Pyrolysis/Gas Chromatography-Mass Spectrometry. Che et al. [26] studied the CFP on metal oxides ( $\mathrm{CaO}, \mathrm{Al}_{2} \mathrm{O}_{3}$, and $\left.\mathrm{ZnO}\right)$, and $\mathrm{ZSM}$ 5 in the dual catalysts method, and found that the combination of metal oxides $\left(\mathrm{CaO}\right.$ and $\left.\mathrm{Al}_{2} \mathrm{O}_{3}\right)$ and ZSM-5 effectively promoted the production of aromatics and reduced the oxygenates. Zhang et al. [27] investigated the dual catalysts with co-CFP of bagasse and bioplastic over HZSM-5 and USY catalysts. It was found that the selectivity towards aromatics such as toluene and xylene were affected by the temperature variations, whereas aromatic benzene was less sensitive to the temperature differences. Liu et al. [28] examined the mixture of CaO and HZSM-5 catalyst with 
co-pyrolysis of corn stover and scum and observed an improvement in the yield of aromatic hydrocarbons. Wang et al. [7] also found that pyrolysis temperature was critically important and selected $600{ }^{\circ} \mathrm{C}$ as the optimum temperature for co-CFP over dual catalytic beds of $\mathrm{MgO}$ and HZSM-5 due to the maximum total peak area of condensable organic products and relative yields of furans and phenols could be reached. $\mathrm{MgO}$ was found to be more favourable for the production of phenols and with the dual catalytic system, it had beneficially increased the yield of aromatics and decreased the yield of acids. Therefore, all these studies have shown that the modification of zeolite with a combination of metal oxides over a dual catalytic method has resulted in a significantly improved mechanism for promoting the yield of aromatics with certain aromatic selectivity. A thorough understanding of the formation of aromatics and the design of catalysts are therefore important in the CFP process to achieve good quality and a large quantity of bio-oil products.

The present work aims to investigate the non-catalytic and catalytic fast co-pyrolysis (co-CFP) of sewage sludge-sawdust by using the Pyrolysis/Gas Chromatography-Mass Spectrometry (Py/GC-MS) instrument at a temperature of $600{ }^{\circ} \mathrm{C}$ and feedstock to catalyst ratio of $1: 1$, to study the effect of metal oxides $\left(\mathrm{NiO}\right.$ and $\left.\mathrm{MoO}_{3}\right)$ and ZSM-5 catalysts on the composition of the pyrolytic products. Catalytic co-pyrolysis of mixed metal oxides (MMOs) of $\left(\mathrm{NiO}+\mathrm{MoO}_{3}\right)$ with the MMOs modified ZSM-5 were also conducted in single and dual catalysts systems. Besides, different methods of catalyst layout were investigated to explore promising effects on the catalytic upgrading conditions.

\section{Materials and methods}

\subsection{Materials}

\subsubsection{Feedstock}

Feedstocks used in this study were sewage sludge, obtained from the Gadong wastewater treatment plant and waste sawdust were collected from Masnor sawmill in Tutong district in Brunei Darussalam. The feedstock was first oven-dried at $105^{\circ} \mathrm{C}$ for $2 \mathrm{~h}$ and then ground and sieved into a fine powder at a diameter of $\leq 250 \mu \mathrm{m}$. Both feedstocks were then mixed using a mortar and pestle at the ratio of 1:2 (sewage sludge: sawdust). Table 1 showing the characteristic of the feedstocks. 
Table 1: Characteristic of feedstocks

\begin{tabular}{cccc}
\hline Analysis & $\begin{array}{c}\text { Sewage sludge } \\
(\mathrm{SS})\end{array}$ & $\begin{array}{c}\text { Sawdust } \\
(\mathrm{SD})\end{array}$ & $\begin{array}{c}(\mathrm{SS}: \mathrm{SD}) \\
(1: 2)\end{array}$ \\
\hline \multicolumn{4}{c}{ Proximate analysis (Wet basis, wt.\%) } \\
\hline Moisture content & 2.57 & 6.07 & 4.90 \\
Volatile matter & 33.60 & 74.30 & 60.30 \\
Ash & 58.40 & 1.73 & 22.30 \\
Fixed carbon* & 5.43 & 17.90 & 12.40 \\
\hline \multicolumn{4}{c}{ Ultimate analysis (Dry basis, wt. \%) } \\
\hline $\mathrm{C}$ & 12.20 & 47.70 & 35.50 \\
$\mathrm{H}$ & 2.47 & 6.06 & 4.57 \\
$\mathrm{~N}$ & 1.83 & 0.13 & 0.70 \\
$\mathrm{~S}$ & 6.28 & 0.00 & 2.09 \\
$\mathrm{O}$ & 18.82 & 44.38 & 34.84 \\
\hline \multicolumn{4}{c}{ Calorific value (Dry basis, MJ/kg) } \\
\hline HHV & 8.04 & 19.30 \\
\hline
\end{tabular}

*By difference

\subsubsection{Catalysts}

Commercial zeolite, ZSM-5 with a specific surface area of approximately $>380 \mathrm{~m}^{2} / \mathrm{g}$, the pore size of $5 \AA$ and $\mathrm{SiO}_{2} / \mathrm{Al}_{2} \mathrm{O}_{3}$ ratio of 30, was obtained from the Advanced Ceramic Esoterica used in this study. Two metal oxides which were nickel oxide $(\mathrm{NiO})$ and molybdenum trioxide $\left(\mathrm{MoO}_{3}\right)$ were obtained from Sigma Aldrich. In this study, both metal oxides (50\% NiO and $50 \% \mathrm{MoO}_{3}$ ) were mixed into mixed metal oxides (MMOs) and MMOs modification with ZSM-5 refers to MMOs $\left(25 \% \mathrm{NiO}+25 \% \mathrm{MoO}_{3}=50 \% \mathrm{MMOs}\right)+\mathrm{ZSM}-5(50 \%)$. The catalyst fractions were combined by their weight ratio using the simple manual blend technique. The catalyst modification was prepared using a mechanical mixing method. Catalysts were mechanically grinding together using natural agate mortar and pestle with ethanol for $1 \mathrm{~h}$ until they dried at room temperature. $\mathrm{NiO}, \mathrm{MoO}_{3}, \mathrm{MMOs}$, and MMOs $+\mathrm{ZSM}-5$ were then calcined at $500^{\circ} \mathrm{C}$ for $4 \mathrm{~h}$ in a muffle furnace, 
while ZSM-5 was calcined at $550{ }^{\circ} \mathrm{C}$ for $5 \mathrm{~h}$. Table 2 lists all the catalysts used in this study. The SEM images of the ZSM-5, NiO, and $\mathrm{MoO}_{3}$ after calcined were shown in Fig. 1.

Table 2: Lists of catalysts

\begin{tabular}{cc}
\hline Catalysts & Method \\
\hline ZSM-5 & Single \\
NiO & \\
\hline MoO 3 & \\
MMOs + ZSM-5 (50:50) & Dual \\
MMOs/ZSM-5 & \\
ZSM-5/MMOs & \\
\hline
\end{tabular}
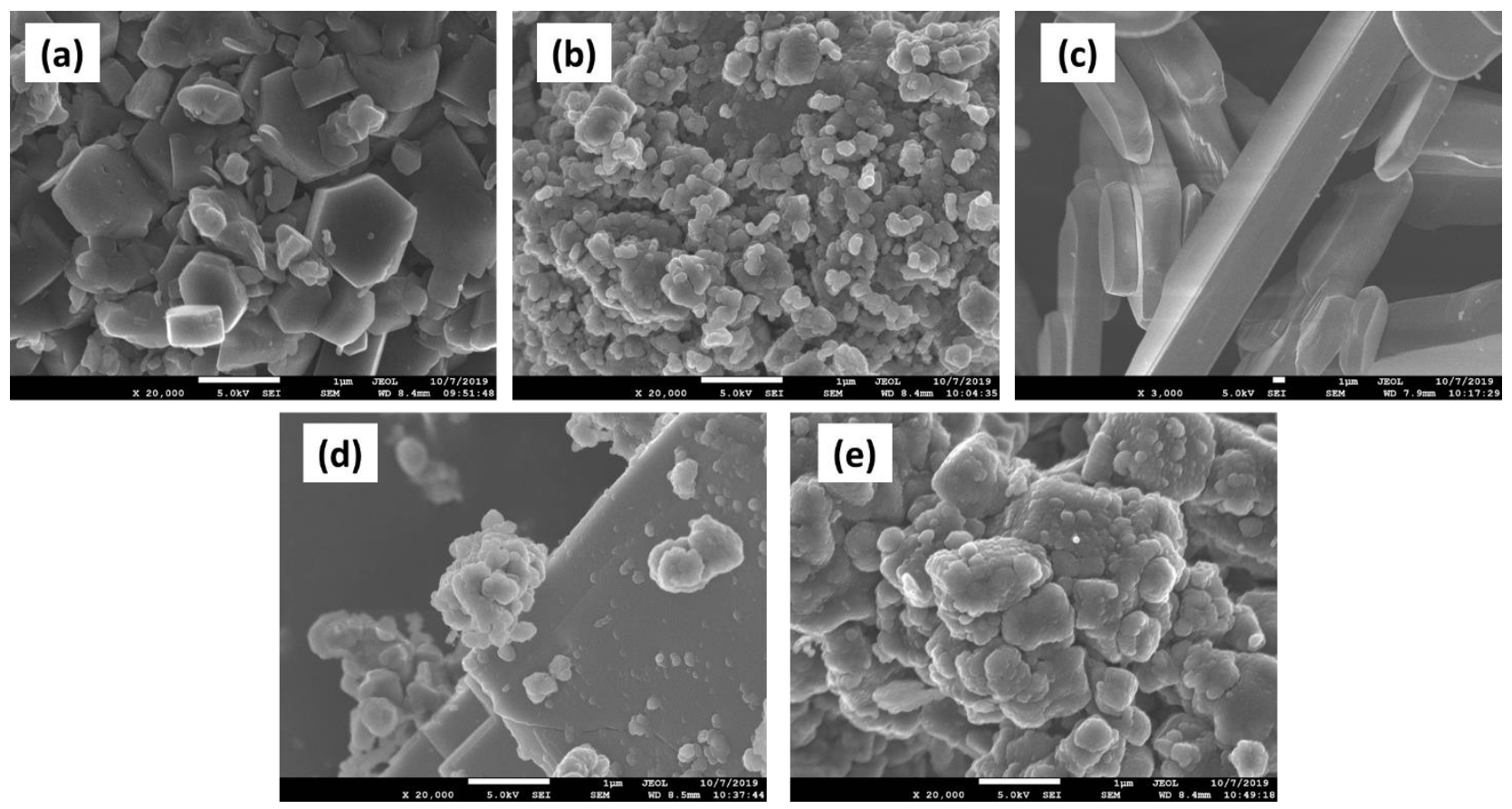

Fig. 1: SEM image of (a) ZSM-5, (b) NiO, (c) $\mathrm{MoO}_{3}$, (d) MMOs and (e) MMOs + ZSM-5 


\subsection{Pyrolysis experiments (Py/GC-MS)}

Catalytic Co-pyrolysis experiments for single and dual catalysts were performed using a chemical data systems (CDS) pyroprobe model 5200 pyrolyzer with connected to the gas chromatography/mass spectrometry (GC/MS) (Shimadzu GC/MS-QP 2010 Ultra) analysis system. The powdered samples were placed in a quartz tube with a dimension of $2 \mathrm{~mm}$ internal diameter and $25 \mathrm{~mm}$. For all experiments, the feedstock to catalysts weight ratio was kept at 1:1. Most researchers use a high catalyst to biomass ratios (3:1 and higher) to see the maximum effect of catalytic conversion. However, a 1:1 ratio is a more realistic scenario that could potentially be used in the real application. The total weight of feedstock and catalysts was fixed at $3.0 \mathrm{mg}$ while for dual catalysts, $1.5 \mathrm{mg}$ for each catalyst. The sample was placed as an in-situ catalytic fast pyrolysis fixed bed system by the following order: glass wool, feedstock, catalysts, glass wool. The specific layouts for the feedstock and catalysts inside the quartz tube are shown in Fig. 2. In all layouts, the feedstock and the catalyst were separated. Layout $\mathrm{A}$ represents $\mathrm{NiO}$ and $\mathrm{MoO}_{3}$ mixed into MMOs. Method B represents MMOs and ZSM-5 mixed together. Layout C and D represent MMOs and ZSM-5 separated with a catalyst loading of MMOs/ZSM-5 and ZSM5/MMOs respectively. A piece of glass wool was required in front and at the back of the sample to prevent any particle from being blown into the vapour transfer line and analysis system that would cause damage. The sample filled quartz tube was placed inside a platinum filament coil heater and positioned at the tip of the pyroprobe. The platinum filament is used as the heating component that can be heated up to $1400{ }^{\circ} \mathrm{C}$ with high purity helium $(99.999 \%)$ injected as the carrier gas. The helium direction was approaching the open-ended quartz tube, while the pyrolysis vapours flowed in one direction from the feedstock and the catalyst to the end of the quartz tube. For each sample, the platinum filament was heated to a constant temperature of $600{ }^{\circ} \mathrm{C}$ and held for $10 \mathrm{~s}$ at a heating rate of $30^{\circ} \mathrm{C} / \mathrm{min}$.

After complete pyrolysis, the vapours product was swept to the transfer line with a carrier gas, high purity helium (99.99\%), to the GC/MS via the GC inlet through the Rtx-5 polar column (30 $\mathrm{m} \times$ Separation of lysate into MS by on-line detection of $0.25 \mathrm{~mm} \times 0.25 \mu \mathrm{m})$ as shown in Fig. 3 . The transfer line temperature was set at $290{ }^{\circ} \mathrm{C}$ to prevent the condensation of vapour during transport. The initial temperature of the $\mathrm{GC}$ part of the oven was set to $40^{\circ} \mathrm{C}$, the inlet temperature was $280^{\circ} \mathrm{C}$, and the split injection method was adopted. The split ratio was 1:50, and the total flow 
rate was controlled to be $54.1 \mathrm{~mL} / \mathrm{min}$. The $\mathrm{GC}$ oven temperature program was set to hold at 40 ${ }^{\circ} \mathrm{C}$ for $4 \mathrm{~min}$, ramp up to $270{ }^{\circ} \mathrm{C}$ at a ramp rate of $8{ }^{\circ} \mathrm{C} / \mathrm{min}$, and maintained for $1 \mathrm{~min}$. The MS was operated in $\mathrm{EI}$ (electron ionization) mode at its energy of $70 \mathrm{eV}$ at the temperature set to $270{ }^{\circ} \mathrm{C}$. The sample product was collected at the scan range between 35 to $500 \mathrm{~m} / \mathrm{z}$ and the overall detection time was for $33.75 \mathrm{~min}$. The GC-MS peak of the pyrolysis product was identified according to the NIST (National Institute of Standards and Technology) MS library standards as well as comparing with literature data. The peak was quantified in terms of chromatographic peak areas. Unfortunately, the Py/GC-MS product, pyrolysis oil could not be collected from the process and therefore mass balanced could not be achieved [29]. Py-GC/MS experiments could not provide quantitative results on the actual yields of compounds in pyrolysis vapours. Hence, an external calibration method was introduced to quantitatively measure the actual yields of certain pyrolytic products [30,31]. In this work, selectivity which was used to evaluate the production of chemicals are defined as follows [30]:

$$
\text { Selectivity }=\frac{\text { Peak area of one compound }}{\text { Total peak area of all compounds }} \times 100 \%
$$

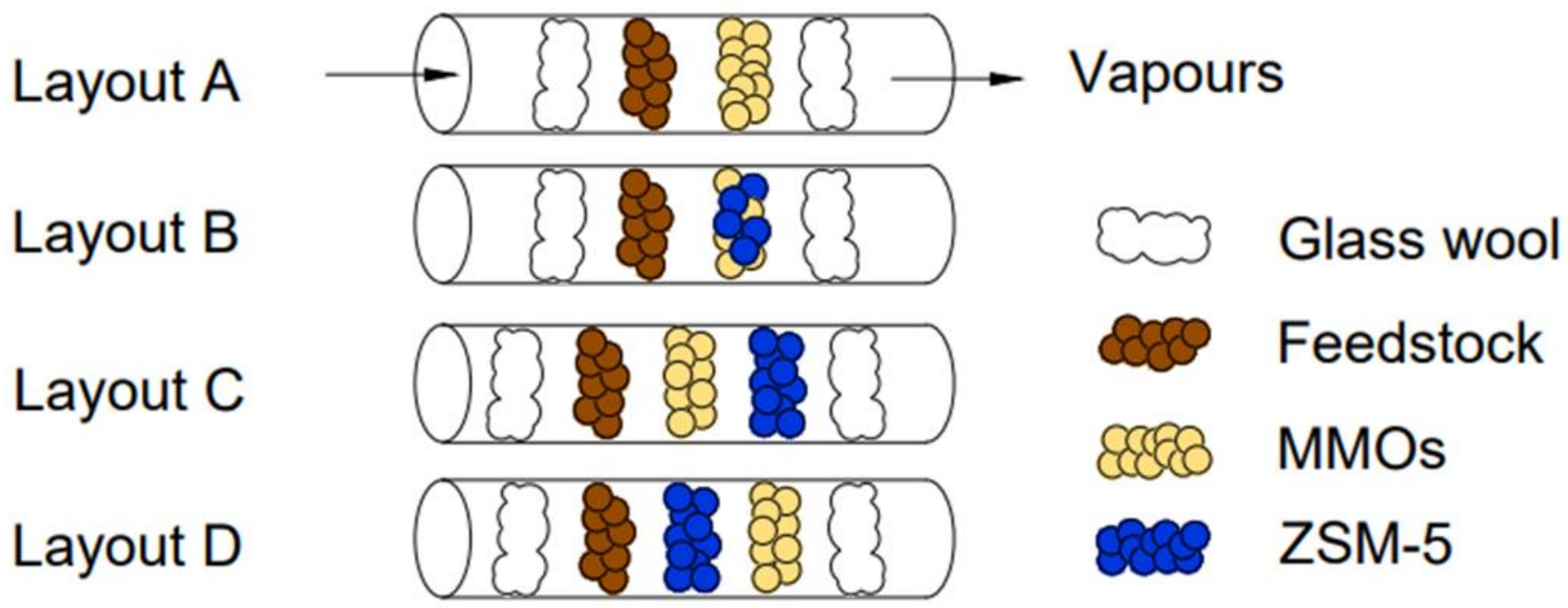

Fig. 2: Specific loading of feedstock and catalysts in dual layout in the quartz tube 


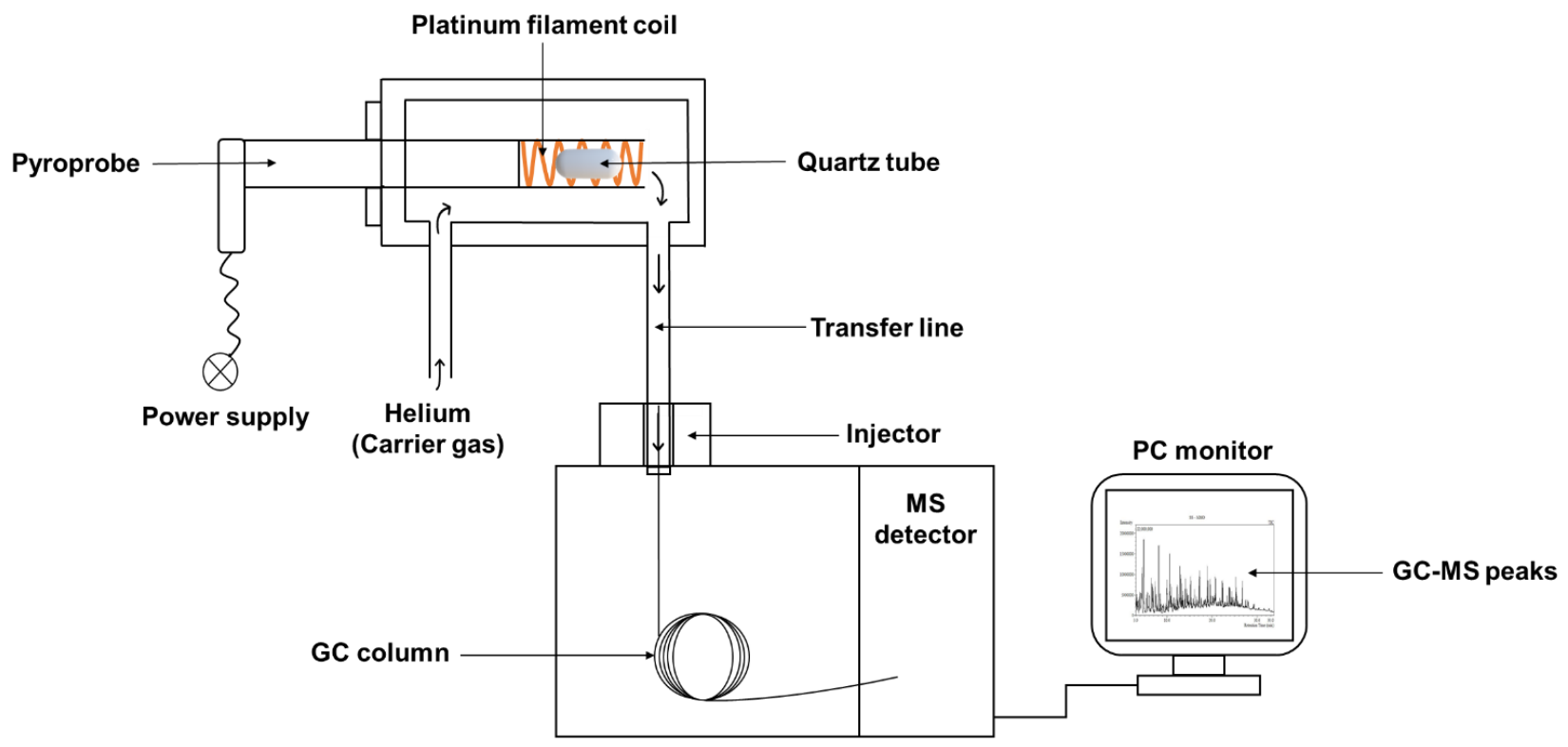

Fig. 3: Py/GC-MS setup

\section{Results and Discussions}

\subsection{Catalytic co-pyrolysis effects with a single catalyst}

Co-CFP experiments with a single catalyst of $\mathrm{NiO}, \mathrm{MoO}_{3}$, and ZSM-5 were conducted first to investigate how the catalysts affected the properties of pyrolytic products. Despite the difficulty for pyrolytic products to be collected from the Py/GC-MS, the peak area of a compound obtained from the GC-MS can be considered linear with its quality whereas the relative peak area \% is with its content. The peak area of the products could be compared to reveal the changes in its yield and the relative peak area \% could show the changes in its relative content in pyrolysis vapours $[32,33]$. The peak areas of the organics products obtained were classified into nine groups which were aliphatic hydrocarbons (HCs), aromatic hydrocarbons, phenols, furans, ketones, nitrogencontaining compounds (NCC), aldehydes, acids, and alcohols were shown in Fig. 4. The details of common compounds found in the co-CFP of sewage sludge and sawdust over ZSM-5, NiO, and $\mathrm{MoO}_{3}$ catalysts are listed in Table 3. It can be seen from Fig. 4, the addition of metal oxide, $\mathrm{NiO}$ reduced both the formation of aliphatic and aromatic hydrocarbons from the non-catalytic while $\mathrm{MoO}_{3}$ increased the aliphatic hydrocarbon but reduced the aromatics formations. $\mathrm{NiO}$ and $\mathrm{MoO}_{3}$ substantially promoted the formation of phenols, ketones, and furans. The formation of ketones 
was due to ketonisation and aldol condensation reaction over metal oxides by promoting $\mathrm{C}-\mathrm{C}$ coupling reactions with the removal of oxygen via dehydration [34]. Furfural had the highest yield that can be promoted in $\mathrm{NiO}$. As with $\mathrm{MoO}_{3}$, it produced only monofunctional furans such as 2,5dimethylfuran. These compounds were undesirable for bio-oil due to their thermal instability [35]. $\mathrm{MoO}_{3}$ increased the formation of $\mathrm{NCC}$ and acids while inhibited aldehyde formation. $\mathrm{MoO}_{3}$ is found to be capable of high formation of acids and NCC [36]. The existence of acids may have a detrimental impact on the properties of bio-oils which would promote the ageing of bio-oils. They are responsible for making bio-oils corrosive to specific metals such as aluminium, mild steel, brass, etc. [37]. NCC that mainly nitriles products are intermediates for an industrial important wide spectrum of commercially valuable chemical products that can be transformed through polymerisation, hydrogenation, hydration, and condensation. The chemical products consist of amines, isocyanates for polyurethanes, phthalocyanine dyes, and vitamin B compounds (niacin) [36]. Nevertheless, NCC is harmful to the environment due to the excess nitrogen in the atmosphere that could lead to the formation of pollutants [38]. ZSM-5 drastically increased the production of aromatic hydrocarbons by $84.2 \%$ than non-catalytic. ZSM-5 is a well-known promising catalyst that can promote deoxygenation in reducing the oxygenates and exhibits a promising effect on the increased formation of aromatic hydrocarbons. With a medium pore size of $5 \AA$ and appropriate acid sites (Bronsted and Lewis acid), the pyrolysis intermediates diffuse into ZSM-5 pores and undergo catalytic cracking on the active sites while cleavage of $\mathrm{C}-\mathrm{O}$ and $\mathrm{C}-\mathrm{C}$ bonds releases oxygen and further transformation produces aromatic hydrocarbons and small molecular weight compounds [39,40]. ZSM-5 exhibited lower formation of acids and alcohols and slightly increased the production of ketones, furans, and NCC in the organic compounds. ZSM-5 resulted in the reduction of acids and alcohol formation from the non-catalytic by $95.6 \%$ and 66.8 $\%$, respectively. ZSM-5 promoted higher phenols formation than metal oxides. Phenols are important due to their potential application as high value-added chemicals, that can be used for the production of plastics and other products [35]. Increased amounts of phenols in the upgraded biooil can indicate a greater ability of the respective catalyst to crack the heavier compounds thus it can be a promising raw material for phenols recovery method [32,41]. $\mathrm{MoO}_{3}$ and ZSM-5 prohibited the aldehyde formation which is beneficial for improving the stability of the catalytic bio-oils since aldehydes are largely responsible for the ageing reactions and instability of bio-oils 
[32]. The above results indicate that the addition of $\mathrm{NiO}$ and $\mathrm{MoO}_{3}$ resulted in major variations in a comparison between the non-catalytic and the ZSM-5 catalyst.
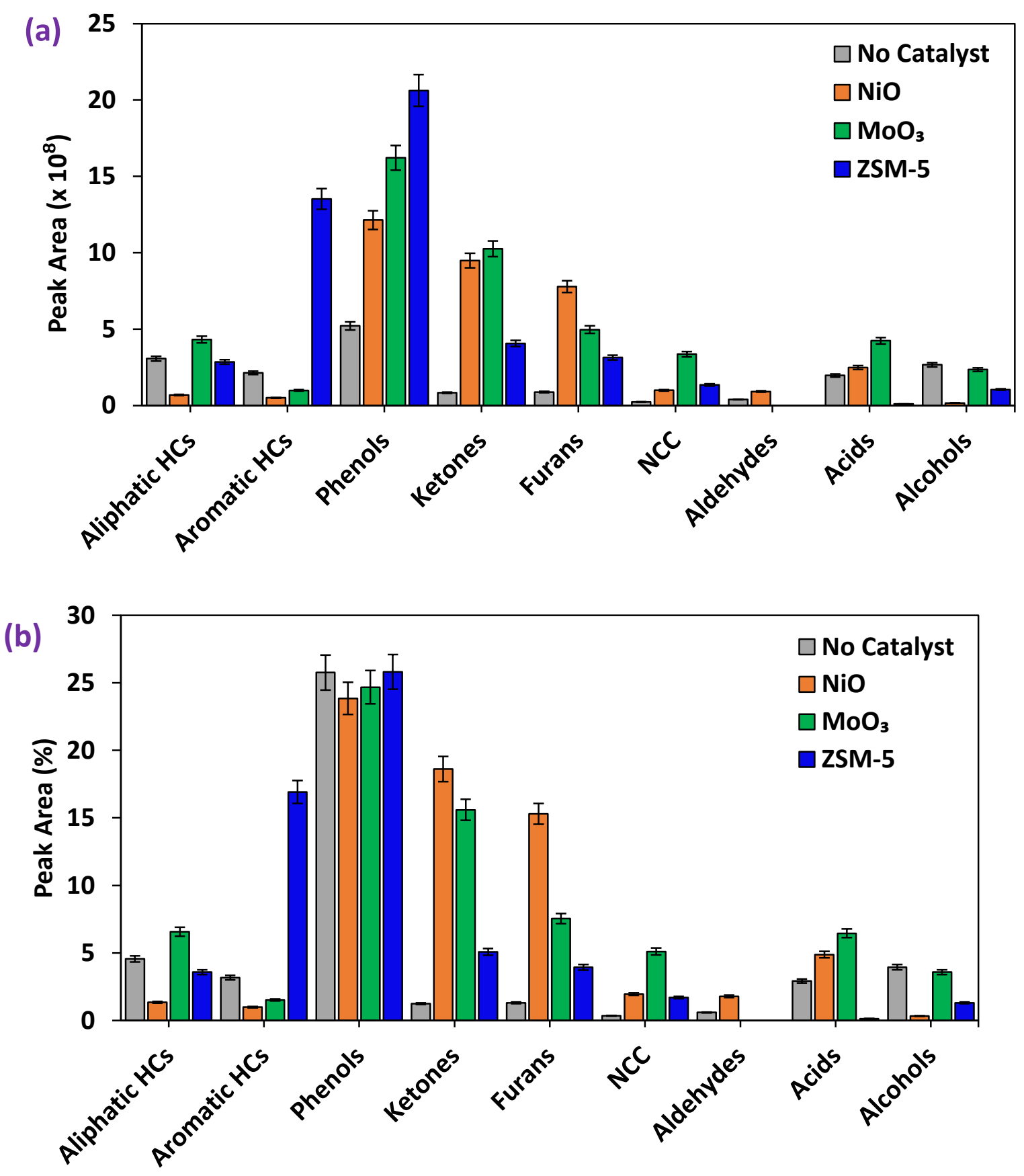

Fig. 4: (a) Peak area and (b) Relative Peak Area (\%) of the products obtained on the effect of catalysts 
Table 3: Common compounds found from co-CFP of sewage sludge and sawdust using ZSM-5, $\mathrm{NiO}$, and $\mathrm{MoO}_{3}$ catalyst

\begin{tabular}{|c|c|c|c|c|}
\hline \multirow{2}{*}{ Name of compound } & \multicolumn{4}{|c|}{ Peak Area (\%) } \\
\hline & No Catalyst & ZSM-5 & $\mathrm{NiO}$ & $\mathrm{MoO}_{3}$ \\
\hline \multicolumn{5}{|l|}{ Aliphatic Hydrocarbon } \\
\hline 1,4-Hexadiene & 0.73 & 0.73 & - & - \\
\hline \multicolumn{5}{|l|}{ Aromatic Hydrocarbon } \\
\hline Toluene & 0.77 & 1.41 & 0.19 & 0.73 \\
\hline o-Xylene & - & 0.77 & - & - \\
\hline \multicolumn{5}{|l|}{ Phenol } \\
\hline Phenol, 2-methyl- & 2.12 & 2.00 & 1.53 & 2.01 \\
\hline Phenol, 2-methoxy- & 5.59 & 4.15 & 5.05 & 5.62 \\
\hline Phenol, 2,4-dimethyl- & 1.26 & 1.88 & 0.73 & - \\
\hline Phenol, 4-ethyl-2-methoxy- & 2.12 & 1.67 & 3.31 & 3.22 \\
\hline Phenol, 2,6-dimethoxy- & 4.32 & 3.18 & 5.00 & 3.91 \\
\hline Eugenol & 4.09 & 5.25 & - & - \\
\hline Phenol, 2,6-dimethoxy-4-(2-propenyl)- & 0.74 & 1.71 & 1.21 & - \\
\hline \multicolumn{5}{|l|}{ Furan } \\
\hline Furan, 2,5-dimethyl- & 0.26 & 0.19 & 0.31 & 0.35 \\
\hline 3-Furaldehyde & - & 0.26 & 0.24 & 4.24 \\
\hline 3-Furanmethanol & - & - & 3.07 & 2.96 \\
\hline Benzofuran, 2,3-dihydro- & 1.04 & 0.38 & 0.86 & - \\
\hline Furfural & - & 2.55 & 3.69 & - \\
\hline \multicolumn{5}{|l|}{ Ketone } \\
\hline 1,2-Cyclopentanedione & - & 4.65 & 6.12 & 6.12 \\
\hline
\end{tabular}




\subsection{Catalytic co-pyrolysis with mixed metal oxides and ZSM-5 catalysts}

Catalytic fast co-pyrolysis on the mixed metal oxides (MMOs) of ( $\mathrm{NiO}+\mathrm{MoO} 3)$ and $\mathrm{MMOs}$ modified with ZSM-5 was conducted to investigate the upgraded version of its organic products. Fig. 5 represents the peak area of MMOs modified ZSM-5 identified compounds which can be divided into four categories: aliphatic hydrocarbons, aromatic hydrocarbons, phenols, and oxygenates (acids, alcohols, ketones, furans, and aldehydes). Peak area of no catalyst added and ZSM-5 alone were included to compare the effect with the MMOs and MMOs modified ZSM-5. It could be seen that ZSM-5 catalysts slightly decreased the aliphatic hydrocarbons production from the non-catalytic by $6.9 \%$. MMOs and MMOs modified ZSM-5 increased the aliphatic hydrocarbons formation by $3.0 \%$ and $31.2 \%$, respectively. When compared with the ZSM-5 alone, the mixing of MMOs into ZSM-5 did increase the production of the aromatics than MMOs. ZSM-5 slightly increased the formation of oxygenates by $19.1 \%$. Instead, both MMOs and the modified ZSM-5 massively increased the oxygenates formation. ZSM-5 could crack smaller oxygenates that can easily enter the catalytic pores and initiate secondary catalytic reactions such as dehydration, decarbonylation, decarboxylation, oligomerisation, and aromatisation reactions at the acidic sites [26].

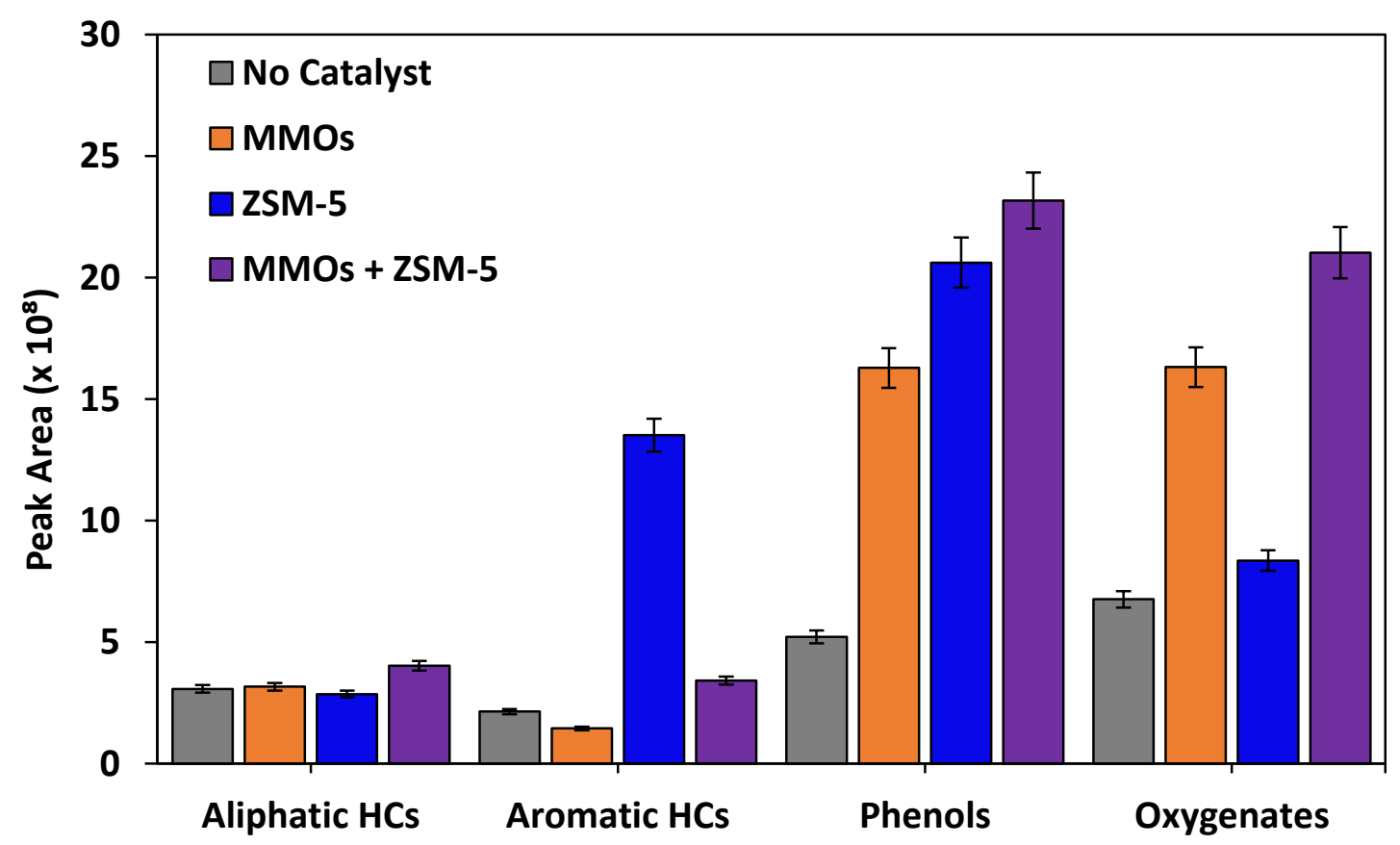

Fig. 5: Peak area of MMOs modified ZSM-5 
The formation of phenols increased both in MMOs and ZSM-5, therefore increased further in MMOs modified ZSM-5. The combination of MMOs with the ZSM-5 catalyst significantly affected the reaction pathway by enhancing the yield of phenols and also the product distribution [42]. The total amount of phenolics for both light and heavy phenols was increased as a result of catalytic upgrading. Fig. 6 clearly illustrated this phenomenon. Light phenols are the phenolic compounds that contain no methoxyl group and no unsaturated $\mathrm{C}-\mathrm{C}$ bonds on the side chain. Heavy phenols are the phenolic compounds that contain methoxyl group or unsaturated C-C bonds on the side chain $[43,44]$. MMOs were able to promote the formation of light phenols (Fig. 6(a)) in the MMOs alone and when modified with ZSM-5 like Phenol, 4-methyl- and Phenol, 2,5-dimethylas compared to the non-catalytic. However, it omitted the phenol, 2,4-dimethyl- that could only be found in the non-catalytic and ZSM-5. MMOs enhanced the conversion of light phenols by deethoxylation, decarbonylation, and cracking, which showed great potential to increase the production of light phenols [7]. However, in Fig. 6(b), the additive of MMOs inhibited the formation of heavy phenols like Phenol, 4-ethyl-2-methoxy- but in the MMOs modified ZSM-5 this compound was largely increased due to its production in the ZSM-5. Phenol, 2,6-dimethoxyis the only heavy phenol that slightly decreased in ZSM-5 and MMOs modified ZSM-5 when compared with the non-catalytic. It can, therefore, be assumed that MMOs and MMOs modified ZSM-5 has the capability to increase both the light and heavy phenols.

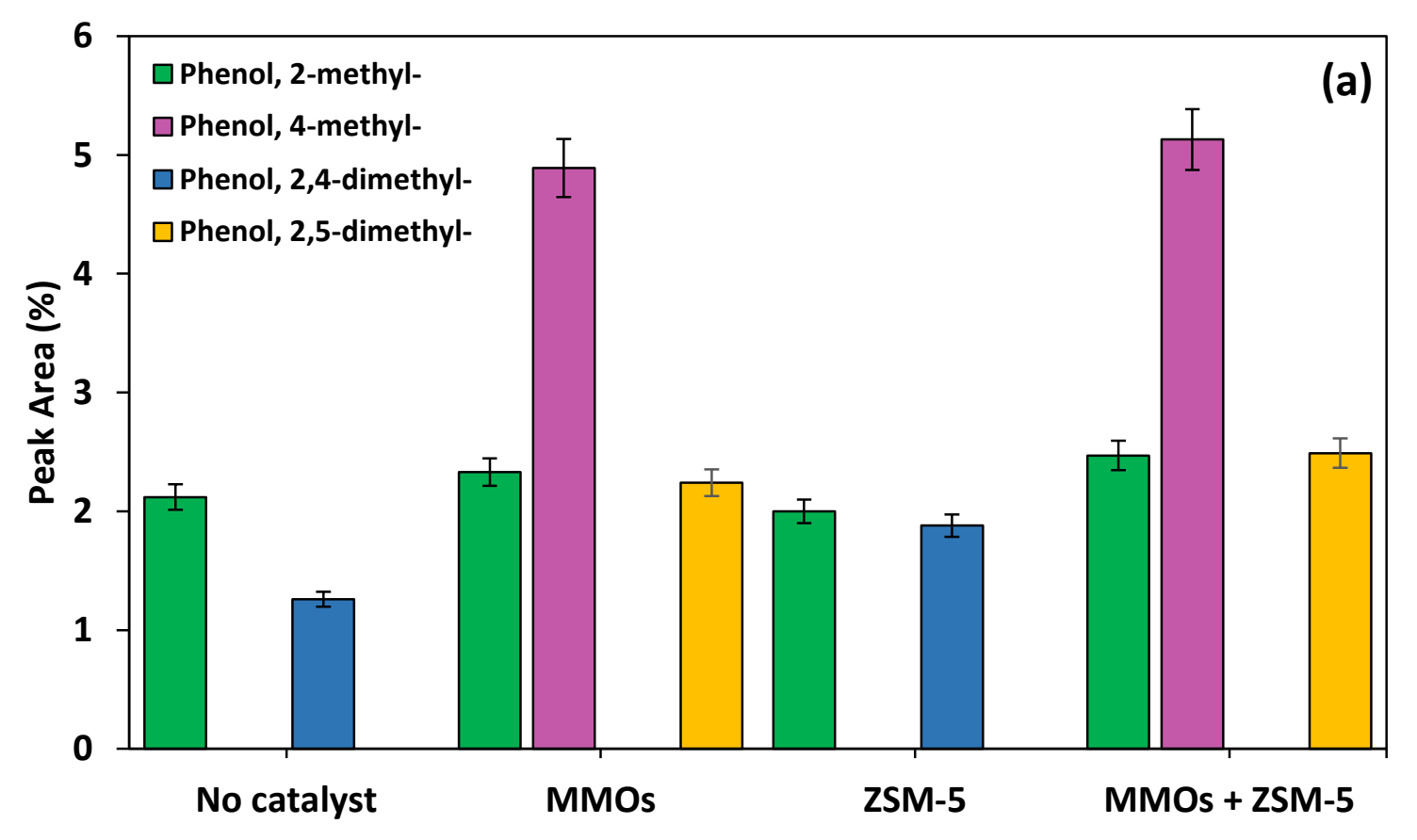




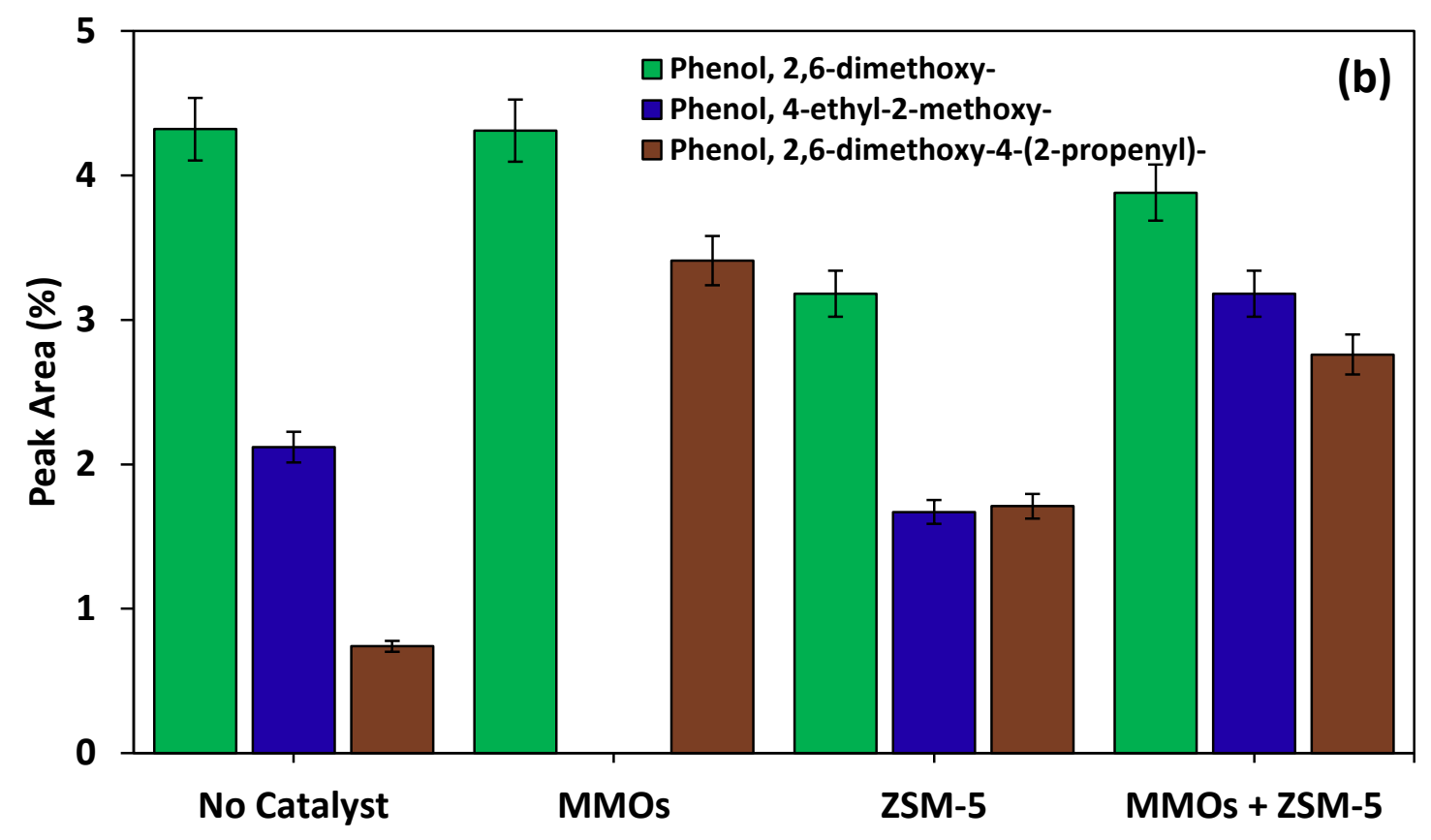

Fig. 6: Effect of catalytic upgrading on the (a) Light phenols and (b) Heavy phenols

Fig. 7 gives details on the selectivity of the aromatic components. It can be observed that aromatics that have not being formed by non-catalytic pyrolysis appeared after catalytic upgrading. Especially due to the addition of ZSM-5, it enhanced the selectivity of monocyclic aromatics mainly benzene, toluene. and xylene (BTX), and polycyclic aromatic hydrocarbons (PAHs). The existence of strong Brönsted acid sites is known to increase the yield of aromatics [45]. ZSM-5 deoxygenated oxygenates and cracked olefins then eliminated from the benzene ring which would then be converted into benzene and other aromatics $[46,47]$. As a result, more monocyclic aromatic hydrocarbons (mainly BTX) and much less coke were produced in the hydrocarbon pool. Aside from that, monocyclic aromatic hydrocarbons and oxygenates may be converted into polycyclic aromatic hydrocarbons (mainly naphthalene and methyl-naphthalene) on the acidic outer surface of ZSM-5 [48]. Hence PAHs were introduced after catalytic pyrolysis. PAHs are a group of undesirable compounds where the emissions could contribute to the potential of carcinogenic and mutagenic products that are dangerous to the human health and environment [38,49]. Besides, PAHs are common precursors of coke formation that could lead to catalytic deactivation and therefore degrade catalytic performance [17]. As compared to the ZSM-5 alone, the addition of MMOs increased remarkably the PAHs contents with $70.5 \%$. It can be concluded that with the 
increase of oxygenates contents (Fig. 5) following the addition of MMOs, the response of monocyclic aromatic hydrocarbons to polycyclic aromatic hydrocarbons has been stimulated, thereby massively increasing the selectivity of PAHs [31]. MMOs did not influence the production of benzene and xylene. Major improvements were also observed in the MMOs modified ZSM-5 aromatics selectivity. The introduction of ZSM-5 to MMOs resulted in the formation of toluene $(33.8 \%)$ and xylene (56.7 \%). It also led to a reduction of $9.5 \%$ in the formation of PAHs due to the concentration of strong ZSM-5 acid sites and the addition of mixed metal oxides, the concentration of both Bronsted and Lewis acid sides of ZSM-5 was reduced [50]. Moreover, the mixed metal oxides deposited on ZSM-5 form Lewis acid sites, adjusting the catalytic performance to prevent additional cracking of vapours [2]. Hence, resulted in the reduction of PAHs formation and a positive effect on the formation of coke on the surface of the catalyst [44].

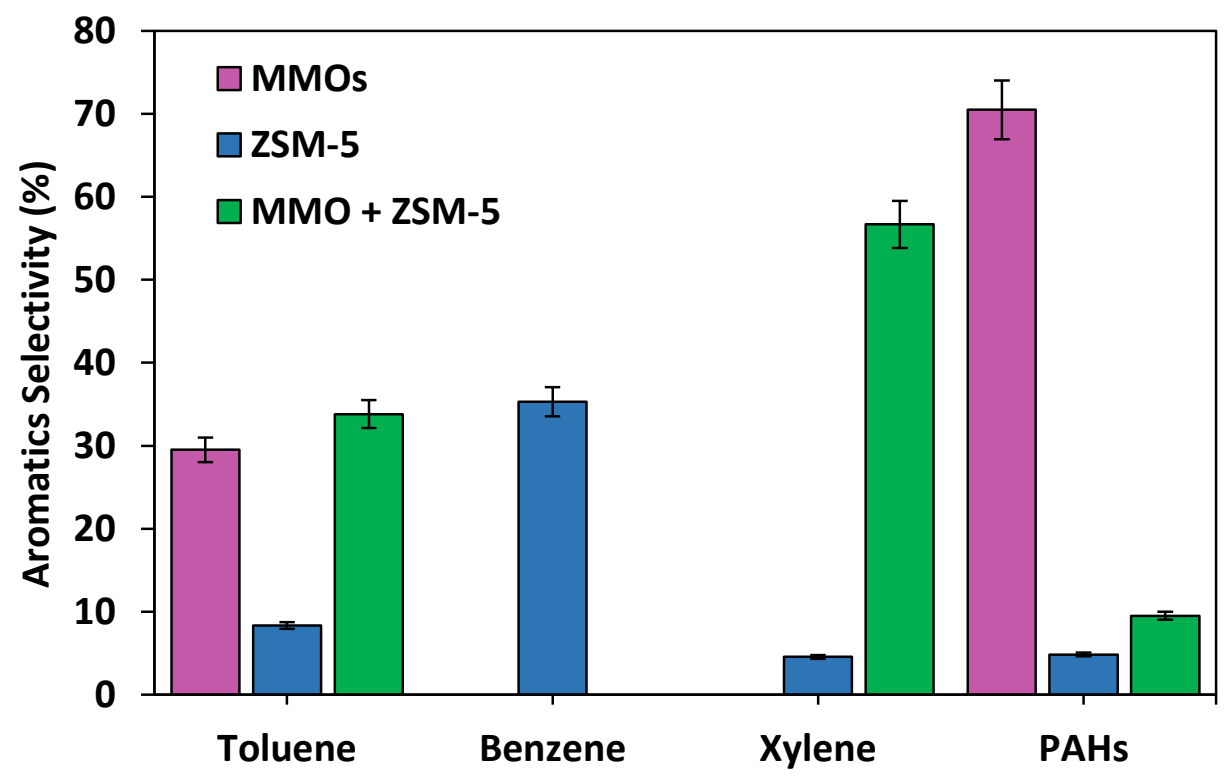

Fig. 7: Aromatics selectivity of MMOs modified ZSM-5

\subsection{Effect of dual-catalysts}

In this study, dual-catalyst co-CFP is investigated in four different layouts. Fig. 8 shows the peak area of product distribution and the aromatics selectivity in each dual-catalyst layout. The peak area which is shown in Fig. 8(a), illustrates that layout B, C, and D, had a positive effect on the upgrading of the production of aromatic hydrocarbons. While layout A (it has been discussed in detail in section 3.2) was found to be the least production of aromatics as compared with other 
layouts. The mixing of MMOs and ZSM-5 in layout B showed to be opposite in the yield of the products with the separated of MMOs and ZSM-5 in layout C and D. The production of aromatics in the layout $\mathrm{B}$ was the lowest when compared to layout $\mathrm{C}$ and $\mathrm{D}$. On the other side, the phenolics produced were the highest. This might be due to the accumulation of MMOs focused more on the outer surface of ZSM-5 instead of entering the pores that contribute to the contamination of the acidic sites. Therefore reducing the activity of the catalyst [51]. The Mixing of catalysts in layout $\mathrm{A}$ and $\mathrm{B}$ increases the phenolics and oxygenates. This could also be seen in oxygenates yield in layout $\mathrm{D}$. Layout $\mathrm{C}$ was found to be balanced in all the product distribution. Among other layouts, the oxygenates production in layout $\mathrm{C}$ was found to be the lowest. Deoxygenation was further enhanced in the secondary reaction by ZSM-5 where deoxygenates from MMOs entered the strong Brönsted site of ZSM-5 would promote the dehydroxylation and demethylation to convert phenols into aromatics [26,52]. Fig. 8(b) presents the aromatics selectivity for different dual catalysts layouts. Layout C promoted the selectivity of BTX and PAHs while layout D inhibited the formation of xylene. The selectivity of toluene decreased in layout $\mathrm{C}$ and $\mathrm{D}$. It is noticeable that MMOs substantially increased the selectivity of PAHs, however with the introduction of ZSM-5 either mixing or separated, it reduced the production tremendously in layout B (9.5\%), C (1.7\%) and $\mathrm{D}(0.8 \%)$. It has been proven that the combination of MMOs with ZSM- 5 must be a promising measure to reduce and inhibit the formation of PAHs.

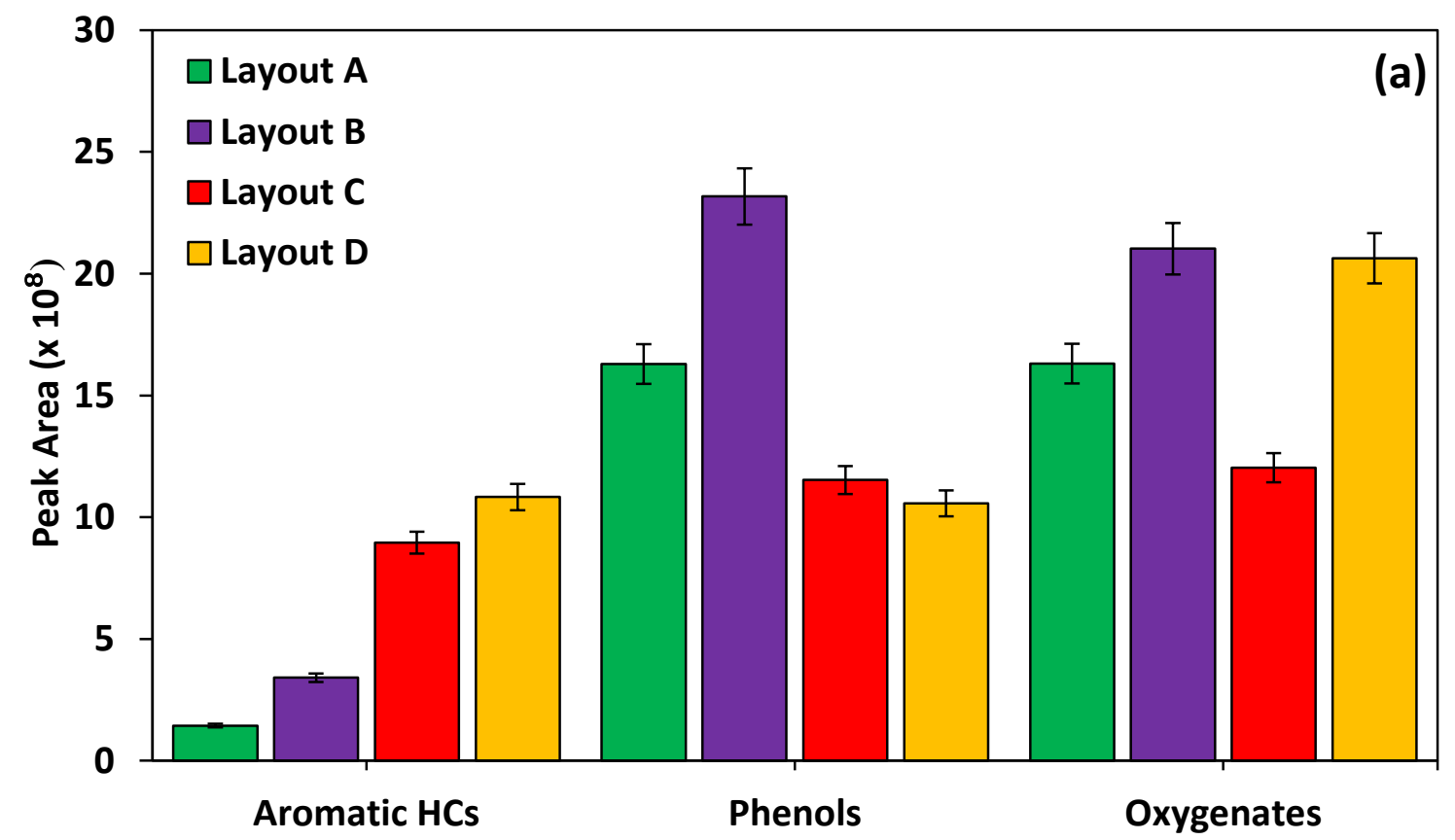




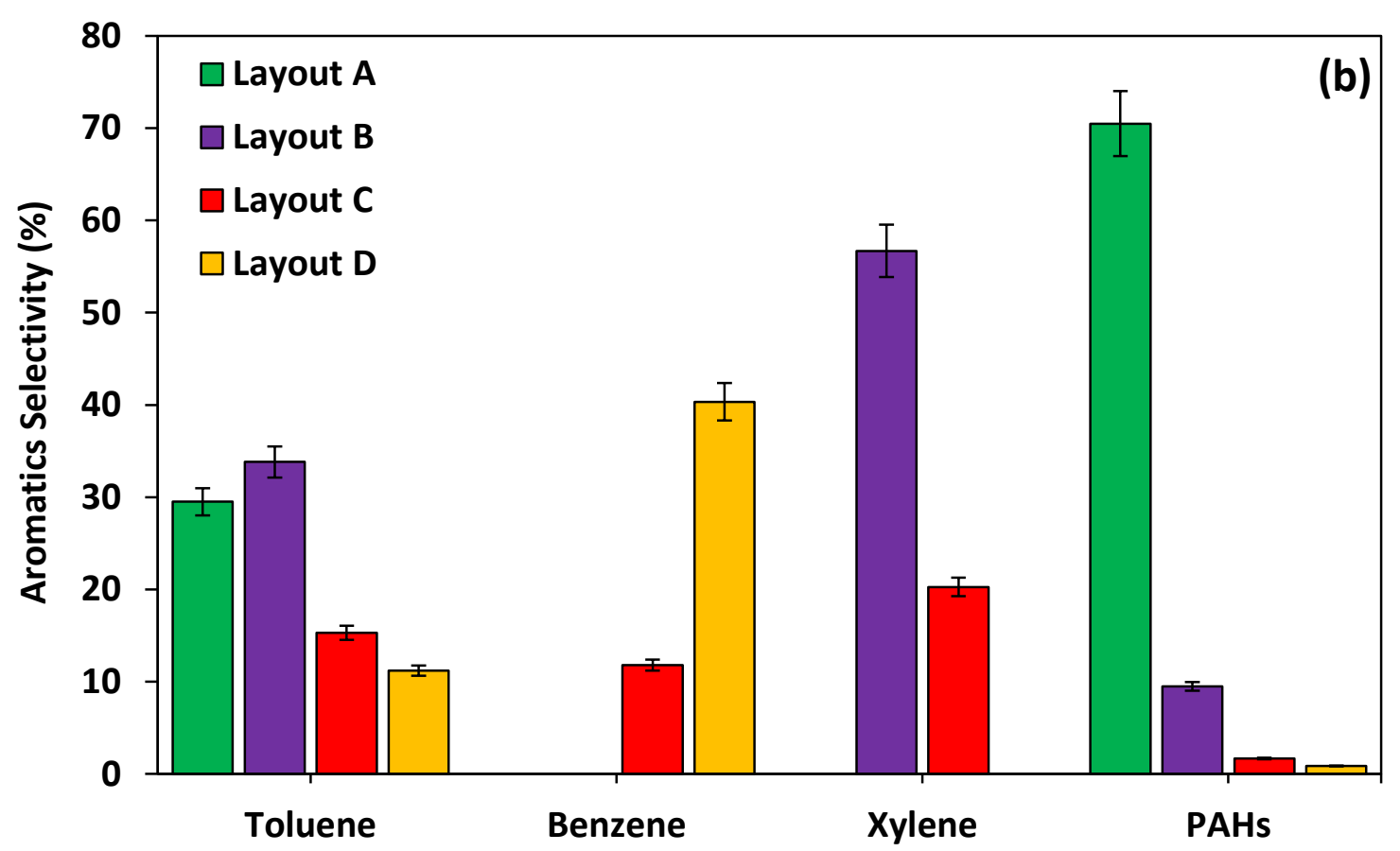

Fig. 8: (a) Peak area of products distribution as a function of dual catalysts layout and (b) Aromatics selectivity for dual-catalysts

\section{Conclusions}

In summary, this paper investigated the distribution of the products from catalytic fast copyrolysis of sewage sludge-sawdust via analytical Py/GC-MS method with mixed metal oxides and modification of ZSM-5 catalysts. The main conclusion that can be drawn is that the combination of mixed metal oxides modified with ZSM-5 effectively affects the reaction pathway of the catalytic upgrading by increasing the production of aromatics and phenols in the products. Aromatics that were not present in non-catalytic pyrolysis were to have appeared after catalytic upgrading. The MMOs and the modified ZSM-5 catalyst were capable to increase both the light and heavy phenols. The formation of undesired PAHs content was remarkably reduced by $70.5 \%$ by the addition of MMOs to ZSM-5 compared to that with the ZSM-5 alone. In further creating promising effects in promoting the production of aromatic hydrocarbons and phenols, the dualcatalysts system with various catalytic layouts has been effective. The dual-catalysts layout of MMOs/ZSM-5 resulted in the optimum catalytic efficiency, promoting more aromatics and phenols and fewer oxygenates and PAHs. 


\section{Acknowledgment}

The authors gratefully appreciate the facility support from the Changsha University of Science and Technology, School of Energy and Power Engineering, and Prince of Songkla University, Department of Chemistry. The main author would like to acknowledge Keith Yeung, Alvin Li, Nur Farah Izzan, Siti Norasyikin, Nur Athirah, Adiib Syazwi, and Ahmed Afif for their assistance in the research procedure.

\section{References}

[1] Y.J. Zhang, J.F. Hao, J. Song, The CO2 emission efficiency, reduction potential and spatial clustering in China's industry: Evidence from the regional level, Appl. Energy. 174 (2016) 213-223. https://doi.org/10.1016/j.apenergy.2016.04.109.

[2] R. Liu, M. Sarker, M.M. Rahman, C. Li, M. Chai, Nishu, R. Cotillon, N.R. Scott, Multiscale complexities of solid acid catalysts in the catalytic fast pyrolysis of biomass for biooil production - A review, Prog. Energy Combust. Sci. 80 (2020). https://doi.org/10.1016/j.pecs.2020.100852.

[3] X. Chen, Q. Che, S. Li, Z. Liu, H. Yang, Y. Chen, X. Wang, J. Shao, H. Chen, Recent developments in lignocellulosic biomass catalytic fast pyrolysis: Strategies for the optimization of bio-oil quality and yield, Fuel Process. Technol. 196 (2019) 106180. https://doi.org/10.1016/j.fuproc.2019.106180.

[4] S. Hidayat, M.S. Abu Bakar, Y. Yang, N. Phusunti, A. V. Bridgwater, Characterisation and Py-GC/MS analysis of Imperata Cylindrica as potential biomass for bio-oil production in Brunei Darussalam, J. Anal. Appl. Pyrolysis. 134 (2018) 510-519. https://doi.org/10.1016/j.jaap.2018.07.018.

[5] T.M.H. Dabros, M.Z. Stummann, M. Høj, P.A. Jensen, J.D. Grunwaldt, J. Gabrielsen, P.M. Mortensen, A.D. Jensen, Transportation fuels from biomass fast pyrolysis, catalytic hydrodeoxygenation, and catalytic fast hydropyrolysis, Prog. Energy Combust. Sci. 68 (2018) 268-309. https://doi.org/10.1016/j.pecs.2018.05.002. 
[6] M.M. Rahman, R. Liu, J. Cai, Catalytic fast pyrolysis of biomass over zeolites for high quality bio-oil - A review, Fuel Process. Technol. 180 (2018) 32-46.

https://doi.org/10.1016/j.fuproc.2018.08.002.

[7] J. Wang, B. Zhang, Z. Zhong, K. Ding, A. Deng, M. Min, P. Chen, R. Ruan, Catalytic fast co-pyrolysis of bamboo residual and waste lubricating oil over an ex-situ dual catalytic beds of MgO and HZSM-5: Analytical PY-GC/MS study, Energy Convers. Manag. 139 (2017) 222-231. https://doi.org/10.1016/j.enconman.2017.02.047.

[8] Y. Xue, A. Kelkar, X. Bai, Catalytic co-pyrolysis of biomass and polyethylene in a tandem micropyrolyzer, Fuel. 166 (2015) 227-236. https://doi.org/10.1016/j.fuel.2015.10.125.

[9] H. Tian, H. Jiao, J. Cai, J. Wang, Y. Yang, A. V. Bridgwater, Co-pyrolysis of Miscanthus Sacchariflorus and coals: A systematic study on the synergies in thermal decomposition, kinetics and vapour phase products, Fuel. 262 (2020) 116603. https://doi.org/10.1016/j.fuel.2019.116603.

[10] L. Zhang, Z. Bao, S. Xia, Q. Lu, K. Walters, Catalytic Pyrolysis of Biomass and Polymer Wastes, 2018. https://doi.org/10.3390/catal8120659.

[11] X. Wu, Y. Wu, K. Wu, Y. Chen, H. Hu, M. Yang, Study on pyrolytic kinetics and behavior: The co-pyrolysis of microalgae and polypropylene, Bioresour. Technol. 192 (2015) 522-528. https://doi.org/10.1016/j.biortech.2015.06.029.

[12] C. Liu, H. Wang, A.M. Karim, J. Sun, Y. Wang, Catalytic fast pyrolysis of lignocellulosic biomass, Chem. Soc. Rev. 43 (2014) 7594-7623. https://doi.org/10.1039/c3cs60414d.

[13] H. Paysepar, K.T.V. Rao, Z. Yuan, H. Shui, C. (Charles) Xu, Improving activity of ZSM5 zeolite catalyst for the production of monomeric aromatics/phenolics from hydrolysis lignin via catalytic fast pyrolysis, Appl. Catal. A Gen. 563 (2018) 154-162. https://doi.org/10.1016/j.apcata.2018.07.003.

[14] Q. Che, M. Yang, X. Wang, Q. Yang, L. Rose Williams, H. Yang, J. Zou, K. Zeng, Y. Zhu, Y. Chen, H. Chen, Influence of physicochemical properties of metal modified ZSM- 
5 catalyst on benzene, toluene and xylene production from biomass catalytic pyrolysis, Bioresour. Technol. (2019) 248-254. https://doi.org/10.1016/j.biortech.2019.01.081.

[15] B. Gu, J.P. Cao, F. Wei, X.Y. Zhao, X.Y. Ren, C. Zhu, Z.X. Guo, J. Bai, W.Z. Shen, X.Y. Wei, Nitrogen migration mechanism and formation of aromatics during catalytic fast pyrolysis of sewage sludge over metal-loaded HZSM-5, Fuel. 244 (2019) 151-158. https://doi.org/10.1016/j.fuel.2019.02.005.

[16] S. Du, D.P. Gamliel, M. V. Giotto, J.A. Valla, G.M. Bollas, Coke formation of model compounds relevant to pyrolysis bio-oil over ZSM-5, Appl. Catal. A Gen. 513 (2016) 6781. https://doi.org/10.1016/j.apcata.2015.12.022.

[17] J. Jae, G.A. Tompsett, A.J. Foster, K.D. Hammond, S.M. Auerbach, R.F. Lobo, G.W. Huber, Investigation into the shape selectivity of zeolite catalysts for biomass conversion, J. Catal. 279 (2011) 257-268. https://doi.org/10.1016/j.jcat.2011.01.019.

[18] Y.T. Cheng, G.W. Huber, Chemistry of furan conversion into aromatics and olefins over HZSM-5: A model biomass conversion reaction, ACS Catal. 1 (2011) 611-628. https://doi.org/10.1021/cs200103j.

[19] B. Huang, X. Xie, Y. Yang, M.M. Rahman, X. Zhang, X. Yu, P.H. Blanco, Z. Dong, Y. Zhang, A. V. Bridgwater, J. Cai, Reaction chemistry and kinetics of corn stalk pyrolysis without and with Ga/HZSM-5, J. Therm. Anal. Calorim. 137 (2019) 491-500. https://doi.org/10.1007/s10973-018-7962-8.

[20] J. Lehto, A. Oasmaa, Y. Solantausta, M. Kytö, D. Chiaramonti, Review of fuel oil quality and combustion of fast pyrolysis bio-oils from lignocellulosic biomass, Appl. Energy. 116 (2014) 178-190. https://doi.org/10.1016/J.APENERGY.2013.11.040.

[21] Y. Yang, J.G. Brammer, J. Samanya, A.K. Hossain, A. Hornung, Investigation into the performance and emissions of a stationary diesel engine fuelled by sewage sludge intermediate pyrolysis oil and biodiesel blends, Energy. 62 (2013) 269-276. https://doi.org/10.1016/j.energy.2013.09.058.

[22] M.B. Gawande, R.K. Pandey, R. V. Jayaram, Role of mixed metal oxides in catalysis 
science - Versatile applications in organic synthesis, Catal. Sci. Technol. 2 (2012) 11131125. https://doi.org/10.1039/c2cy00490a.

[23] I.A. Vasalos, A.A. Lappas, E.P. Kopalidou, K.G. Kalogiannis, Biomass catalytic pyrolysis: Process design and economic analysis, Wiley Interdiscip. Rev. Energy Environ. 5 (2016) 370-383. https://doi.org/10.1002/wene.192.

[24] M.B. Griffin, K. Iisa, H. Wang, A. Dutta, K.A. Orton, R.J. French, D.M. Santosa, N. Wilson, E. Christensen, C. Nash, K.M. Van Allsburg, F.G. Baddour, D.A. Ruddy, E.C.D. Tan, H. Cai, C. Mukarakate, J.A. Schaidle, Driving towards cost-competitive biofuels through catalytic fast pyrolysis by rethinking catalyst selection and reactor configuration, Energy Environ. Sci. 11 (2018) 2904-2918. https://doi.org/10.1039/c8ee01872c.

[25] X. Chen, Y. Chen, H. Yang, X. Wang, Q. Che, W. Chen, H. Chen, Catalytic fast pyrolysis of biomass: Selective deoxygenation to balance the quality and yield of bio-oil, Bioresour. Technol. 273 (2019) 153-158. https://doi.org/10.1016/j.biortech.2018.11.008.

[26] Q. Che, M. Yang, X. Wang, X. Chen, W. Chen, Q. Yang, H. Yang, H. Chen, Aromatics production with metal oxides and ZSM-5 as catalysts in catalytic pyrolysis of wood sawdust, Fuel Process. Technol. 188 (2019) 146-152. https://doi.org/10.1016/j.fuproc.2019.02.016.

[27] H. Zhang, P.K.W. Likun, R. Xiao, Improving the hydrocarbon production via co-pyrolysis of bagasse with bio-plastic and dual-catalysts layout, Sci. Total Environ. 618 (2018) 151156. https://doi.org/10.1016/j.scitotenv.2017.11.045.

[28] S. Liu, Q. Xie, B. Zhang, Y. Cheng, Y. Liu, P. Chen, R. Ruan, Fast microwave-assisted catalytic co-pyrolysis of corn stover and scum for bio-oil production with $\mathrm{CaO}$ and HZSM-5 as the catalyst, Bioresour. Technol. 204 (2016) 164-170. https://doi.org/10.1016/j.biortech.2015.12.085.

[29] M. Zhang, F.L.P. Resende, A. Moutsoglou, Catalytic fast pyrolysis of aspen lignin via PyGC/MS, Fuel. 116 (2014) 358-369. https://doi.org/10.1016/j.fuel.2013.07.128.

[30] H. Zhang, X. Meng, C. Liu, Y. Wang, R. Xiao, Selective low-temperature pyrolysis of 
microcrystalline cellulose to produce levoglucosan and levoglucosenone in a fixed bed reactor, Fuel Process. Technol. 167 (2017) 484-490.

https://doi.org/10.1016/j.fuproc.2017.08.007.

[31] Q. Lu, H. qiang Guo, M. xing Zhou, M. shu Cui, C. qing Dong, Y. ping Yang, Selective preparation of monocyclic aromatic hydrocarbons from catalytic cracking of biomass fast pyrolysis vapors over Mo2N/HZSM-5 catalyst, Fuel Process. Technol. 173 (2018) 134142. https://doi.org/10.1016/j.fuproc.2018.01.017.

[32] Q. Lu, Y. Zhang, Z. Tang, W.Z. Li, X.F. Zhu, Catalytic upgrading of biomass fast pyrolysis vapors with titania and zirconia/titania based catalysts, Fuel. 89 (2010) 20962103. https://doi.org/10.1016/j.fuel.2010.02.030.

[33] Y. Yang, J.G. Brammer, M. Ouadi, J. Samanya, A. Hornung, H.M. Xu, Y. Li, Characterisation of waste derived intermediate pyrolysis oils for use as diesel engine fuels, Fuel. 103 (2013) 247-257. https://doi.org/10.1016/j.fuel.2012.07.014.

[34] J. Wang, C. Xu, Z. Zhong, A. Deng, N. Hao, M. Li, X. Meng, A.J. Ragauskas, Catalytic Conversion of Bamboo Sawdust over $\mathrm{ZrO} 2-\mathrm{CeO} 2 / \hat{\mathrm{I}}-\mathrm{A} 12 \mathrm{O} 3$ to Produce Ketonic Hydrocarbon Precursors and Furans, ACS Sustain. Chem. Eng. 6 (2018) 13797-13806. https://doi.org/10.1021/acssuschemeng.8b01873.

[35] C.A. Mullen, P.C. Tarves, A.A. Boateng, Role of Potassium Exchange in Catalytic Pyrolysis of Biomass over ZSM-5: Formation of Alkyl Phenols and Furans, ACS Sustain. Chem. Eng. 5 (2017) 2154-2162. https://doi.org/10.1021/acssuschemeng.6b02262.

[36] J.C. Védrine, Heterogeneous catalysis on metal oxides, Catalysts. 7 (2017). https://doi.org/10.3390/catal7110341.

[37] Q. Lu, J. Zhang, X. Zhu, Corrosion properties of bio-oil and its emulsions with diesel, Chinese Sci. Bull. 53 (2008) 3726-3734. https://doi.org/10.1007/s11434-008-0499-7.

[38] E.F. Iliopoulou, S.D. Stefanidis, K.G. Kalogiannis, A. Delimitis, A.A. Lappas, K.S. Triantafyllidis, Catalytic upgrading of biomass pyrolysis vapors using transition metalmodified ZSM-5 zeolite, Appl. Catal. B Environ. 127 (2012) 281-290. 
https://doi.org/10.1016/j.apcatb.2012.08.030.

[39] Nishu, R. Liu, M.M. Rahman, M. Sarker, M. Chai, C. Li, J. Cai, A review on the catalytic pyrolysis of biomass for the bio-oil production with ZSM-5: Focus on structure, Fuel Process. Technol. 199 (2020) 106301. https://doi.org/10.1016/j.fuproc.2019.106301.

[40] M.M. Rahman, M. Chai, M. Sarker, Nishu, R. Liu, Catalytic pyrolysis of pinewood over ZSM-5 and CaO for aromatic hydrocarbon: Analytical Py-GC/MS study, J. Energy Inst. 93 (2020) 425-435. https://doi.org/10.1016/j.joei.2019.01.014.

[41] V.K. Guda, H. Toghiani, Catalytic pyrolysis of pinewood using metal oxide catalysts in an integrated reactor system, Biofuels. 8 (2017) 527-536. https://doi.org/10.1080/17597269.2016.1231960.

[42] Y. Shi, E. Xing, K. Wu, J. Wang, M. Yang, Y. Wu, Recent progress on upgrading of biooil to hydrocarbons over metal/zeolite bifunctional catalysts, Catal. Sci. Technol. 7 (2017) 2385-2415. https://doi.org/10.1039/c7cy00574a.

[43] X. Zhang, L. Sun, L. Chen, X. Xie, B. Zhao, H. Si, G. Meng, Comparison of catalytic upgrading of biomass fast pyrolysis vapors over $\mathrm{CaO}$ and $\mathrm{Fe}(\mathrm{III}) / \mathrm{CaO}$ catalysts, $\mathrm{J}$. Anal. Appl. Pyrolysis. 108 (2014) 35-40. https://doi.org/10.1016/j.jaap.2014.05.020.

[44] E.F. Iliopoulou, K.S. Triantafyllidis, A.A. Lappas, Overview of catalytic upgrading of biomass pyrolysis vapors toward the production of fuels and high-value chemicals, Wiley Interdiscip. Rev. Energy Environ. 8 (2019) 1-29. https://doi.org/10.1002/wene.322.

[45] M.-J. Jeon, S.-S. Kim, J.-K. Jeon, S.H. Park, J.M. Kim, J.M. Sohn, S.-H. Lee, Y.-K. Park, Catalytic pyrolysis of waste rice husk over mesoporous materials, Nanoscale Res. Lett. 7 (2012) 18. https://doi.org/10.1186/1556-276x-7-18.

[46] P.A. Lazaridis, A.P. Fotopoulos, S.A. Karakoulia, K.S. Triantafyllidis, Catalytic fast pyrolysis of kraft lignin with conventional, mesoporous and nanosized ZSM-5 zeolite for the production of alkyl-phenols and aromatics, Front. Chem. 6 (2018). https://doi.org/10.3389/fchem.2018.00295. 
[47] C.A. Mullen, A.A. Boateng, Catalytic pyrolysis-GC/MS of lignin from several sources, Fuel Process. Technol. 91 (2010) 1446-1458.

https://doi.org/10.1016/j.fuproc.2010.05.022.

[48] T.R. Carlson, J. Jae, G.W. Huber, Mechanistic insights from isotopic studies of glucose conversion to aromatics over ZSM-5, ChemCatChem. 1 (2009) 107-110. https://doi.org/10.1002/cctc.200900130.

[49] Y. Hu, W. Yu, H. Wibowo, Y. Xia, Y. Lu, M. Yan, Effect of catalysts on distribution of polycyclic-aromatic hydrocarbon (PAHs) in bio-oils from the pyrolysis of dewatered sewage sludge at high and low temperatures, Sci. Total Environ. 667 (2019) 263-270. https://doi.org/10.1016/j.scitotenv.2019.02.320.

[50] J. Fermoso, H. Hernando, P. Jana, I. Moreno, J. Přech, C. Ochoa-Hernández, P. Pizarro, J.M. Coronado, J. Čejka, D.P. Serrano, Lamellar and pillared ZSM-5 zeolites modified with $\mathrm{MgO}$ and $\mathrm{ZnO}$ for catalytic fast-pyrolysis of eucalyptus woodchips, Catal. Today. 277 (2016) 171-181. https://doi.org/10.1016/j.cattod.2015.12.009.

[51] V. Paasikallio, C. Lindfors, E. Kuoppala, Y. Solantausta, A. Oasmaa, J. Lehto, J. Lehtonen, Product quality and catalyst deactivation in a four day catalytic fast pyrolysis production run, Green Chem. 16 (2014) 3549-3559. https://doi.org/10.1039/c4gc00571f.

[52] J. Wang, Q. Liu, J. Zhou, Z. Yu, Production of High-Value Chemicals by Biomass Pyrolysis with Metal Oxides and Zeolites, Waste and Biomass Valorization. (2020). https://doi.org/10.1007/s12649-020-00962-1. 